\title{
Impact of menopausal symptoms on quality of life among women's in Qena city.
}

\section{Reda R. Ali, Sayed A. Mohamed Taha, Manal F. Moustafa \& Sahar F. El saied}

Assistant lecturer of obstetrics and Gynecological Nursing- Faculty of Nursing- South Valley University. professor of obstetrics and Gynecological medicine- Faculty of Medicine- South Valley University. professor of obstetrics and Gynecological Nursing - Faculty of Nursing- Assuit University. lecturer of obstetrics and Gynecological Nursing- Faculty of Nursing- South Valley University.

\begin{abstract}
Background: Menopause, the time when a woman stops having menstrual periods, is not a disease or an illness for most women, menopause is a normal occurrence.. The most common age range at which women experience menopause is 48-55 years. Aim of the study: To assess the Impact of menopausal symptoms on quality of life among women's in Qena City. Subject and Method: it was a descriptive study and a convenient sample included 250 menopausal women. Data was collected through a questionnaire to collect necessary data. Setting: The study was conducted at out patient's clinics of Qena University and general hospitals and south valley university. Results: the study results revealed that there was a positive strong correlation between MRS and QOL $(r=0.878)$. Conclusion : It can be concluded that post-menopausal women in this study had severe menopausal symptoms and this had adversely affected on quality of life. Recommendations: Implement appropriate health educational programs are essential for improving the quality of life of menopausal women in Qena city.
\end{abstract}

\section{Keywords: Menopausal Symptoms, Quality Of Life \& Women.}

\section{Introduction}

Menopause is defined as the permanent cessation of menses. The age at which natural menopause occurs is between the ages of 45 and 55 years for women worldwide. ( Ashrafi,et al., 2010). Menopause is a physiological event in the women's life. Natural menopause is recognized after 12 months of amenorrhea that is not associated with a pathologic cause. (Rahman et al., 2010) .

It is caused by aging of ovaries which leads to decline in the production of ovarian Gonadotrophins Estrogen and Progesterone. that occurs naturally or is induced by surgery ,chemotherapy, or radiation. The deficiency of these hormones elicits various somatic, vasomotor, sexual and psychological symptoms that impair the overall quality of life of women. (Lu et al., 2007). Menopausal age consider the end of the fertile phase of a woman's life. (Walker et al., 2008). The menopausal symptoms effects on a woman's behavior and psychological status, resulting in extremely unpleasant symptoms. ( Ashrafi, et al., 2010) .

The mean age of the menopause in Egypt is 46.7 years, which is low compared to many countries, but this age has been rising in the past few years in the west, probably because of the different sociocultural attitudes' towards the menopause in different communities.(Sallam, et al., 2006)

Effects that are due to low estrogen levels (for example vaginal atrophy and skin drying) will continue after the menopause transition years are over; however, many effects that are caused by the extreme fluctuations in hormone levels (for example hot flashes and mood changes) usually disappear or improve significantly once the perimenopause transition is completely over. All the various possible perimenopause effects are caused by an overall drop, as well as dramatic but erratic fluctuations, in the absolute levels and relative levels of estrogens and progesterone. Effects such as formication (crawling, itching, or tingling skin sensations), may be associated directly with hormone withdrawal. (TwissJ, et al., 2007). Both users and non-users of hormone replacement therapy (HRT) identify lack of energy as the most frequent and distressing effect. Other effects can include vasomotor symptoms such as hot flashes and palpitations, psychological effects such as depression, anxiety, irritability, mood swings, memory problems and lack of concentration, and atrophic effects such as vaginal dryness and urgency of urination. Other common effects encountered during the perimenopausal period include mood changes, insomnia, fatigue, and memory problems. (Arakane, et al., 2011).

Menopause can be officially declared (in an adult woman who is not pregnant, is not lactating, and who has an intact uterus) when there has been amenorrhea (absence of any menstruation) for one complete year. However, there are many signs and effects that lead up to this point, many of which may extend well beyond it too. These include: irregular menses, vasomotor instability (hot flashes and night sweats), atrophy of genitourinary tissue, increased stress, 
breast tenderness, vaginal dryness, forgetfulness, mood changes, and in certain cases osteoporosis and/or heart disease. (Thacker, 2011). The World Health Organization (WHO) (1994) defines quality of life (QOL) as an individual's perception of their position in life in the context of the culture and value system in which they live and in relation to their goals, expectations, standards and concerns. Quality of life (QOL) is a very important public health issue. By definition quality of life is a subjective parameter and direct questionioning is therefore a simple and appropriate way of obtaining information about how patients feels and function. In the transitional age of Menopauses, women often experience a variety of symptoms affecting their quality of life. These may involve different areas such as: physical (including most frequently vasomotor symptoms); psychosocial, mood, sleep; and the sexual sphere. (Pensri, et al., 2007).

Nursing role during menopause as a counselor about menopausal symptoms and its effects on quality of life and aware women with this problems and how to deal with it and nurse as educator about this period as changing lifestyle that help women to reduce menopausal symptoms, maintain bone density and reduce risk of heart disease as Eat a healthy diet, including at least five portions of different colored fruit and vegetables every day, Maintain or take steps to achieve a healthy body weight, sleep in a cool room, sleep in a well-ventilated room and use lightweight bedding, Develop effective ways of dealing with stress and learn to relax and take regular moderate exercise, and especially weight bearing activity and resistance training to maintain lean body mass. (Royall College of Nursing(RCN), 2009).

\section{Significance of the study}

Health-care providers need to play a more visible and instrumental role in continuously assessing menopausal women's needs as well as to implement appropriate health educational programs and to develop a new way to meet their demands. So, standardized measures are needed to assess changes of quality of life arising from menopause. (Gharaibeh, et al., 2010).

\section{Aim of the study}

To assess the impact of menopausal symptoms on quality of life among women's in Qena City.

\section{Subject and method}

\section{I-Research design}

A descriptive study design was utilized in carrying out this study.

\section{II-Study Settings}

The study was conducted at out patient's clinics of Qena University and general hospitals such as obstetrics and gynecological clinic and the orthopedic clinic(because decrease flow of subjects in other places of data collections), the maternal and child health center of sedy abdel-Rahim in Qena, and South Valley University, which provide free services all cases from rural and urban areas at qena city, Egypt.

\section{III- Research Questions}

1. Is there was a correlation exist between menopausal symptoms and quality of life?

\section{IIII- Population Sample}

convenient sample included 250 menopausal women, which ages ranged between 45 and 60 years, who were seeking medical advice or not. Direct personal communication made to get their consent and cooperation before being enrolled in the study after the purpose of the study was explained. This sample detected by using Epi- info ${ }^{\mathrm{tm}}$ statistical package, version 3.3 with power $80 \%$, a value of 2.5 is chosen as the acceptable limit of precision (D) at $95 \%$ level of confidence ( CI ), sample size was estimated to be 250 women. The collected data started from MayAugust ,2013 which are collected through two-three days per week.

The target population of the study was chosen according to the following criteria

Inclusion criteria:-The study population included: 1. All the women who had attained natural menopause .

2. Whose age ranged between 45 to 60 years .

3. Who had symptoms of menopause.

Exclusion criteria

1. Women had chronic diseases before menopause

2. Women who had undergone overectomy, hysterectomy or chemotherapy .

\section{Tools of data collection}

A structured interview sheet that was developed, modified and translated and utilized by the researcher to collect the necessary data to filled from the menopausal women in Qena city . it was based on review of literature and reviewed by experts from nursing obstetrics and Gynecological nursing specialties.it included the following three tools:

Tool I: Socio - demographic data sheet used to collect data about the study subject (as age, education, employment, marital status and residence) and reproductive parameters (menstrual history, gravidity, and parity ).

Tool II: Menopausal Rating scale (MRS).

It was developed by (Heinemenn, et al., 2003) It comprises of 11 items assessing menopausal symptoms, divided into three subscales. A) Somatic: included hot flushes, heart discomfort, sleep problem 
and muscles and joint problems. B) Psychological: included depression, irritability, anxiety and physical and mental exhaustion. And C) Urogenital: included Sexual problems, bladder problems and dryness of vagina translated by the researcher. Each item answered points by using four points rating scale begin from $(0)=$ not present $),(1)=$ mild $),(2)=$ moderate), $(3)=$ severe $),(4)=$ very severe $)$.

Tool III: The World Health Organization quality of life (WHOQOL) ( Brief questionnaire in Urdu Version) was used for it. It was developed by (Skevington, et al., 2004) and translated into Arabic language and modified by the researcher to be suitable for the study. It was used for assessment of health related quality of life (HRQOL).

It consisted of 26 items, categorized under 4 main domains described asfollows:-

1.Physical domain: was concerned with nutritional status ,sleep status (sleep hours, effect of menopausal symptoms on sleep) and sexual efficacy(sexual relation and satisfaction after menopause)

2. Psychological domain: was concerned with effect of menopause on psychological condition, effect of psychological effect on work.

3.Social domain: was concerned with social activities and hobbies before menopause as reading, housing work, visiting the relatives and friends...etc. and effect of menopause on these activities and hobbies.

4. Environmental domain: was concerned with environmental evaluation, effect of menopause on environmental activities and effect of weather on menopausal symptoms as cold, heat and heat \&cold environment.

\section{Scoring system}

Poor QOL :- from 0 to $33.3 \%$

Average QOL:- from $33.3 \%$ to $66.7 \%$

Good QOL :- more than $66.7 \%$.

\section{Ethical consideration}

- The consent was obtained from women orally before being involved in the study after explanation of the nature and purpose of the study and there are no risks or cost in participation, and there are voluntary participation and confidentiality of each subject who agree to participate and to fill the questionnaire.

- The researcher was assured voluntary participation and confidentiality of each subject who agrees to participate.

- The researcher introduced herself to the eligible women and briefly explained the nature of the study and the then researcher was interviewed the participant face to face to answer a questionnaire, the first contact between the researcher and the study participants at the out patients clinics or in place of participant in south valley university during this interview, the questionnaire was obtained and answered question to assess the severity of menopausal symptoms and its effect on quality of life of women.

- Privacy and confidentiality of the study data was asserted and the obtained data was available only to the researcher and the participants.

\section{Procedure}

- An official permission was obtained from the head of department of obstetrics \& gynecology in Qena university hospital, mother and child health center and consent from subjects that participate in the study after the purpose and nature of the study was explained for taking their approval to carry out the study.

- The researcher takes two to three days every week, and each day take about 5 women maximally.

- The filling of questionnaire took 30-45 minutes by participants.

- After filling the questionnaire the researcher was explained symptoms to women for awareness and answered the questions of participant related to this subject and the researcher provided health education about menopausal problems or effects and how deals with it and was give women brochure about menopausal symptoms and its management.

- Brochure was in Arabic language, consist of two pages and its contents were definition ,changes during menopause, menopausal symptoms and its managements, and life styles that support this period.

\section{Pilot study}

It was conducted in (10\% equal 25 women) from sample size menopausal which was included in the study, this pilot was done to identify the clarity of the questions and test validity and reliability of the questionnaire.

\section{Statistical analysis}

Data collected were coded and analyzed. Results were tabulated and statistically compared by computer program (SPSS) SD, number, percentage and using Chi-square to determine significance between numerical variable. N.S P>0.05 (No significance), $\mathrm{P}<0.05$ (Significance). 


\section{Results}

Table (1): Distribution of Menopausal Women According to Socio - Demographic Characteristics.

\begin{tabular}{|c|c|c|}
\hline Socio-demographic characteristics & No. $=\mathbf{2 5 0}$ & $\%$ \\
\hline Mean \pm SD & \multicolumn{2}{|c|}{$53.6 \pm 6.5$} \\
\hline - $45-50$ years & 52 & 20.8 \\
\hline - 50 - 55 years & 85 & 34.0 \\
\hline$\checkmark 55-60$ years & 113 & 45.2 \\
\hline \multicolumn{3}{|l|}{ Residence } \\
\hline - Rural & 189 & 75.6 \\
\hline Urban & 61 & 24.4 \\
\hline \multicolumn{3}{|l|}{ Who do you live with? } \\
\hline Alone & 21 & 8.4 \\
\hline with family & 222 & 88.8 \\
\hline with relatives & 7 & 2.8 \\
\hline \multicolumn{3}{|l|}{ Occupation } \\
\hline Worker & 48 & 19.2 \\
\hline - house wife & 202 & 80.8 \\
\hline \multicolumn{3}{|l|}{ level of education } \\
\hline Illiterate & 168 & 67.2 \\
\hline - read and write & 28 & 11.2 \\
\hline primary school & 9 & 3.6 \\
\hline - secondary school & 39 & 15.6 \\
\hline University & 6 & 2.4 \\
\hline \multicolumn{3}{|l|}{ social status } \\
\hline - Single & 9 & 3.6 \\
\hline - Married & 163 & 65.2 \\
\hline - Widow & 69 & 27.6 \\
\hline Divorced & 9 & 3.6 \\
\hline
\end{tabular}

Table (2): Distribution of women according to reproductive history.

\begin{tabular}{|l|c|c|}
\hline \multicolumn{1}{|c|}{ History of menstruation } & No.=250 & \% \\
\hline Age at menarche & 142 & 56.8 \\
\hline 9-12 years & 107 & 42.8 \\
\hline 14-16 years & 1 & 0.4 \\
\hline$\quad$ more than 16 years & 217 & 86.8 \\
\hline Regularity of menstruation & 33 & 13.2 \\
\hline Regular & \multicolumn{2}{|c|}{} \\
\hline Irregular & 30 & 12.0 \\
\hline Frequency of menstruation & 158 & 63.2 \\
\hline less than 21 days & 53 & 21.2 \\
\hline 21-25 days & 9 & 3.6 \\
\hline 25-35 days & \multicolumn{2}{|l|}{} \\
\hline
\end{tabular}




\begin{tabular}{|c|c|c|}
\hline History of menstruation & No. $=250$ & $\%$ \\
\hline \multicolumn{3}{|l|}{ Duration of menstruation } \\
\hline - 3 days & 53 & 21.2 \\
\hline 5 days & 158 & 63.2 \\
\hline$\bullet 7$ days & 39 & 15.6 \\
\hline \multicolumn{3}{|l|}{ Amount of menstruation } \\
\hline$\checkmark$ Heavy & 46 & 18.4 \\
\hline - Moderate & 193 & 77.2 \\
\hline$\bullet \quad$ Mild & 11 & 4.4 \\
\hline \multicolumn{3}{|l|}{ Number of pregnancy } \\
\hline$\bullet \quad 0$ (null- gravid) & 30 & 12.0 \\
\hline $1-5$ times & 101 & 40.4 \\
\hline More than 5 times & 119 & 47.6 \\
\hline \multicolumn{3}{|l|}{ Number of labor } \\
\hline$\bullet \quad 0$ (null-para) & 30 & 12.0 \\
\hline $1-5$ times & 114 & 45.6 \\
\hline More than 5 times & 106 & 42.4 \\
\hline
\end{tabular}

Table(3): Distribution of women according to menopausal rating scale (MRS).

\begin{tabular}{|c|c|c|}
\hline Items & No. $=\mathbf{2 5 0}$ & $\%$ \\
\hline (1) Somatic symptoms & \multicolumn{2}{|c|}{$3.73 \pm 0.56$} \\
\hline$\rightarrow \quad$ None & 2 & 0.8 \\
\hline - Light & 18 & 7.2 \\
\hline Moderate & 81 & 32.4 \\
\hline Severe & 93 & 37.2 \\
\hline very severe & 56 & 22.4 \\
\hline Heart problems & \multicolumn{2}{|c|}{$3.65 \pm 0.55$} \\
\hline$\rightarrow \quad$ None & 0 & 0 \\
\hline Light & 34 & 13.6 \\
\hline - Moderate & 59 & 23.6 \\
\hline Severe & 117 & 46.8 \\
\hline very severe & 40 & 16 \\
\hline Sleep problems & \multicolumn{2}{|c|}{$3.74 \pm 0.56$} \\
\hline None & 2 & 0.8 \\
\hline$\checkmark$ Light & 27 & 10.8 \\
\hline Moderate & 46 & 18.4 \\
\hline Severe & 133 & 53.2 \\
\hline very severe & 42 & 16.8 \\
\hline Joints and muscles problem & \multicolumn{2}{|c|}{$3.76 \pm 0.56$} \\
\hline None & 6 & 2.4 \\
\hline$\rightarrow$ Light & 11 & 4.4 \\
\hline Moderate & 63 & 25.2 \\
\hline Severe & 128 & 51.2 \\
\hline very severe & 42 & 16.8 \\
\hline
\end{tabular}




\begin{tabular}{|c|c|c|}
\hline Items & No. $=\mathbf{2 5 0}$ & $\%$ \\
\hline (2) Psychological symptoms(Mood depression) & \multicolumn{2}{|c|}{$3.44 \pm 0.52$} \\
\hline None & 11 & 4.4 \\
\hline$\rightarrow$ Light & 26 & 10.4 \\
\hline - Moderate & 82 & 32.8 \\
\hline Severe & 103 & 41.2 \\
\hline very severe & 28 & 11.2 \\
\hline Anxiety & \multicolumn{2}{|c|}{$3.50 \pm 0.53$} \\
\hline None & 6 & 2.4 \\
\hline Light & 23 & 9.2 \\
\hline Moderate & 89 & 35.6 \\
\hline Severe & 103 & 41.2 \\
\hline very severe & 29 & 11.6 \\
\hline Worry & \multicolumn{2}{|c|}{$3.80 \pm 0.57$} \\
\hline$\bullet \quad$ None & 2 & 0.8 \\
\hline Light & 16 & 6.4 \\
\hline - Moderate & 52 & 20.8 \\
\hline Severe & 145 & 58.0 \\
\hline very severe & 35 & 14.0 \\
\hline (3) Uro- genital symptoms ( Sexual problems) & \multicolumn{2}{|c|}{$3.66 \pm 0.55$} \\
\hline None & 3 & 1.2 \\
\hline Light & 19 & 7.6 \\
\hline - Moderate & 96 & 38.4 \\
\hline Severe & 73 & 29.2 \\
\hline very severe & 59 & 23.6 \\
\hline Urinary bladder problems & \multicolumn{2}{|c|}{$3.82 \pm 0.57$} \\
\hline none & 2 & 0.8 \\
\hline - light & 29 & 11.6 \\
\hline moderate & 55 & 22.0 \\
\hline severe & 90 & 36.0 \\
\hline very severe & 74 & 29.6 \\
\hline Dryness of vagina & \multicolumn{2}{|c|}{$2.82 \pm 0.42$} \\
\hline$\bullet$ none & 35 & 14.0 \\
\hline light & 60 & 24.0 \\
\hline moderate & 75 & 30.0 \\
\hline severe & 74 & 29.6 \\
\hline very severe & 6 & 2.4 \\
\hline
\end{tabular}

Table (4): Levels of menopausal symptoms among studied subjects.

\begin{tabular}{|l|c|c|c|}
\hline & No.=250 & \% & \multirow{2}{*}{ P. value } \\
\hline Mild & 39 & 15.6 & \multirow{2}{*}{ 0.001** } \\
\cline { 1 - 3 }$\bullet$ Moderate & 76 & 30.4 & \\
\hline Severe & 135 & 54.0 & \\
\hline
\end{tabular}


Fig:(1): The relation between menopausal symptoms and the quality of life of women.

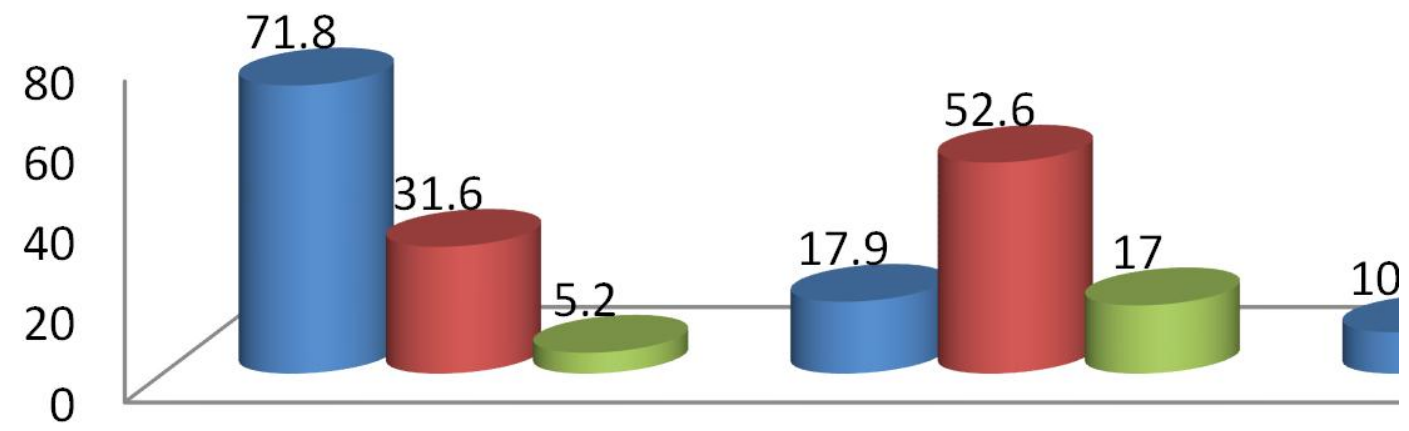

Fig: (2): The effect of menopausal symptoms on quality of life (physical ,psychological ,social, and environmental activity).

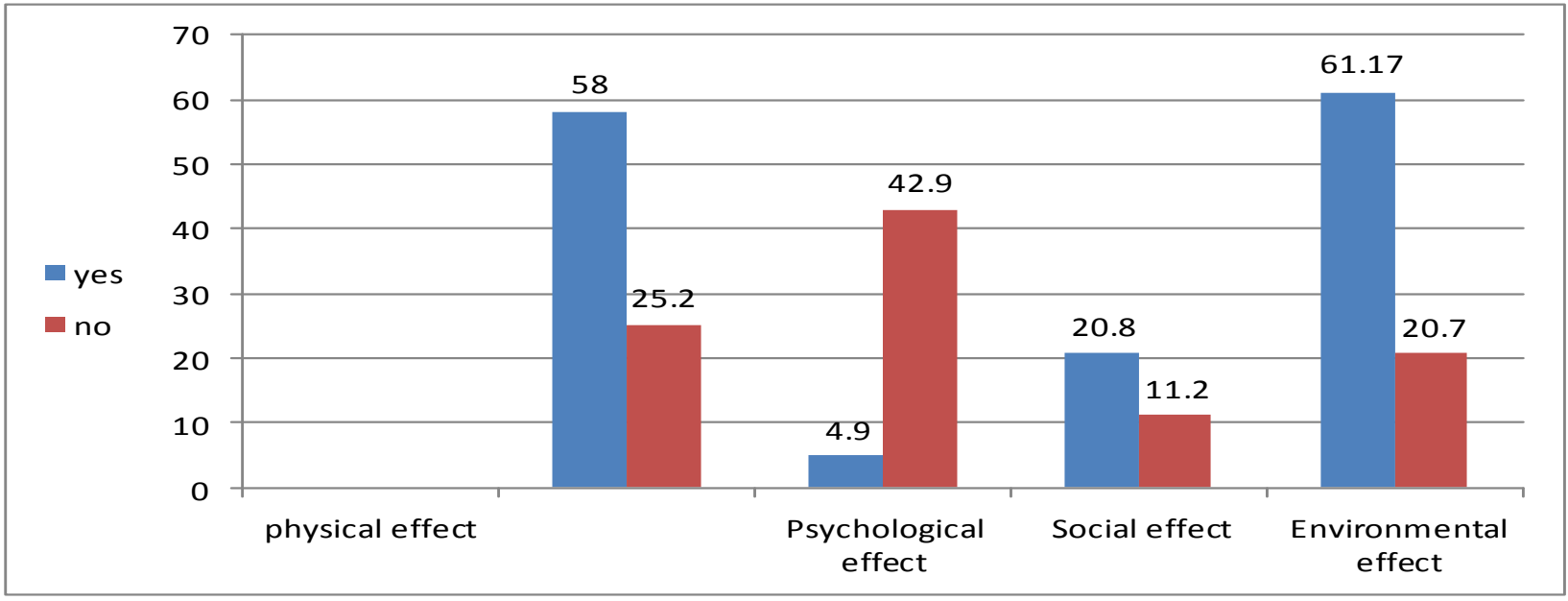

Fig: (2): The effect of menopausal symptoms on quality of life (physical ,psychological ,social, and environmental activity).

Table(1): show that slightly less than half of women about $(45.2 \%)$ were in the age group 55-60 years old. And slightly more than one- fifth of women about $(20.8 \%)$ were in the age group 45-50 years old, with

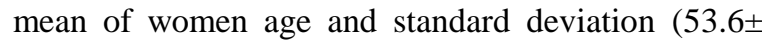
6.5 .

Regarding to residence, slightly more than threefourth of women about $(75.6 \%)$ were from rural area and slightly more than one-fifth of women about $(24.4 \%)$ were from urban area.

In the same table, regarding to occupation, the great majority of women about $(80.8 \%)$ house wife and less than one -seventh of women about $(19.2 \%)$ were worker. As regarding to level of

education of menopausal women ,more than twothird of women about ( $67.2 \%)$ have illiterate and less than one- seventh of women about (2.4\%) have university education .
Regarding to social status, less than one-seventh of women about $(3.6 \%)$ were single and divorced and slightly less than two- thirds of women about $(65.2 \%)$ were married.

Table(2): the results show that ,regarding age of menarche ,less than half of women about (42.8\%) were have menarche at age group 14-16years old ,and slightly more than half of women about $(56.8 \%)$ were have menarche at age group 9-12 years old.

Regarding to regularity of periods ,the majority of women about (86.8\%) were have regular periods.

In the same table, regarding amount of period, slightly more than three- fourth of women about $(77.2 \%)$ were have moderate period and less than one- fifth of women about (18.4\%) were have heavy period.

the results show that, regarding number of pregnancy, less than one- sixth of women about (12\%) were not have pregnancy (null-gravida), less than half of women about (47.6\%) were have more than five times of pregnancy. 
Table(3): the results show, menopausal rating scale, regarding to vasomotor symptoms regarding to, hot flushes and night sweating, more than one- third of women about $(37.2 \%)$ were have severe hot flushes , slightly less than one- third of women about (32.4\%) were have answered moderate , and slightly more than one -fifth about $(22.4 \%)$ were have answered very severe.

In the same table regarding to heart problems, less than one half of women about $(46.8 \%)$ were severe and slightly less than one - fourth about (23.6\%) were moderate.

As regarding to sleep problems, more than one -half of women about $(53.2 \%)$ were severe and less than one- fifth about (18.4\%) were have answered moderate.

In the same table, regarding to, joints and muscles problems, slightly more than one- half of women about $(51.2 \%)$ were severe ,and slightly more than one- fourth about $(25.2 \%)$ were moderate.

Regarding psychological symptoms regarding to mood depression, less than one-half about (41.2\%) were severe, less than one - seventh about (4.4\%) were none.

Regarding to physical \&mental stress, more than one - half about $(58.0 \%)$ were severe and one - fifth about $(20.8 \%)$ were moderate.

In the same table , regarding to urinary and genital system symptoms, as regarding to sexual problems, more than one - third about $(38.4 \%)$ were moderate and less than one- third about $(29.2 \%)$ were severe.

Regarding dryness of vagina, less than one- third about $(30.0 \%$ ) were moderate , and the minority of them about $(2.4 \%)$ were very severe.

Table (4): the results show menopausal rating scale levels, less than one - sixth of women about $(15.6 \%)$ were have good MRS level and more than one-half of them about $(54.0 \%)$ were have poor MRS level, with mean \pm SD about $(42.3+14.4)$, so there was statistical significance difference.

fig(1): The result show the correlation between MRS and QOL , more than three-fourth of women about (77.8\%) with poor quality of life and with poor MRS , so there was statistical significance difference, and There was a positive strong correlation between MRS and QOL.

Fig :(2): This figure shows that effect of menopausal symptoms on quality of life, regarding physical status more than half of women $(58.0 \%)$ answered "yes" and regarding psychological status the minority of them $(4.9 \%)$ answered "yes" or affected, So there was a statistically significant difference.

\section{Discussion}

The term "menopause" denotes the final cessation of menstruation, either as a normal part of aging or as the result of surgical removal of both ovaries. Some of menopausal symptoms experienced by these women can be severe enough to affect their normal daily activities .The common climacteric symptoms experienced by them can be group into: vasomotor, physical, psychological or sexual complaints (Gharaibeh, et al., 2010).

In the present study, carried at on women with, the Mean age (53.6+6.5) and it is found that slightly less than one- half of women (48.4\%) with poor quality of life. with average and poor QOL. and there was strong correlation ( $r>0.878$ ) between QOL \&MRS with statistical significant $\mathrm{p}<0.001$.

The current study revealed that the mean of age of study subjects was $53.6 \pm 6.5$ years, this agree with study conducted by (Dhillon et al., 2006) and (palacios et al., 2010) who reported that the mean age at menopause was $51.14 \pm 2.11$ years, and also, agrees with another study conducted by (Delaver, et al., 2011) who stated that the mean age in menopause was 47.7years.

The present work revealed that most of women (47.6\%) had high parity more than 5 times, this agree with.(castelo-Branco, et al., 2005) who mentioned that the most of these women $(84 \%)$ had a high parity rate $(<4)$ in their A study in a rural farming population of native- Bolivian Movima menopausal women $(n=125)$.

The present study revealed that the most prevalent symptoms in the MRS score: (37.2\%), Hot flushes was severe degree. this agree with ( Yakout, et al., 2011) who mentioned that the majority $(85.0 \%)$ of women have severe degree of hot flushes in their study about Menopausal Symptoms and Quality of Life among Saudi Women in Riyadh and Taif .

In my point view, the present study indicated an overall increase prevalence of menopausal symptoms in studied population. The reasons for different frequencies can be many as the menopausal symptoms are influenced by sociodemographic/sociocultural factors, economical stresses, general health status, individual perception of menopause, genetic and racial differences and reproductive parameters like parity.

The present study show that, more than one - third (38.4\%) of women have moderate sexual problems and this disagree with (Yakout, et al., 2011) who mentioned that more than one- half $(62.5 \%)$ of women have severe sexual problems in their study about Menopausal Symptoms and Quality of Life among Saudi Women in Riyadh and Taif . 
The present study illustrated that positive correlation between quality of life and MRS scores this disagree with (yakout,et al., 2011 )who mentioned that there was the negative significant correlation between MRS scores and WHOQOL Brief scores in social, environmental domains, and over all mean score of quality of life for postmenopausal women.

In my point of view, In the present study menopause is seen in a negative way because of the association with the end of fertility and the end of youth. And this , had a highly negative impact on both their quality of life, as expressed by physical and psychological symptoms, as well as by a high prevalence of sexual dysfunction. These facts are of special concern, because of the unequal access to health care and the weak social protection systems in the countries in Egypt.

\section{Conclusion}

It can be concluded that post-menopausal women in this study had severe menopausal symptoms and this had adversely affected on quality of life. and there was a strong positive correlation between MRS and QOL.

\section{Recommendation}

Based on results of the present study the following recommendations are suggested

I. healthcare providers must play a role clearly \& understand the symptoms and pathological conditions associated with climacteric, and must provide individual women with health care to improve their QOL and prevent diseases that particularly affect women undergoing menopause.

II. implement appropriate health educational programs are essential for improving the quality of life of menopausal women in Qena city.

\section{References}

1. Arakane M., Castillo C., Rosero M., Peñafiel R., Pérez-López F., Chedraui P., (2011): "Factors relating to insomnia during the menopausal transition as evaluated by the Insomnia Severity Index.". Maturitas 69 (2): pp. 157-161. PMID 21444163.

2. Castelo-Branco C., Palacios S., Mostajo D., et al., (2005): Menopausal transition in Movima women, a Bolivian nativeAmerican. Maturitas 2005;51:380-5

3. Ashrafi M., Kazemi, S., (2010): Symptoms of natural menopause among Irania $\mathrm{n}$ women who were living in Tehran. Iranian Journal of Reproductive Medicine, 2010; 8: 29-32.
4. Delavar1 M., and Hajiahmadi M., (2011): Factors Affecting the Age in Normal Menopause and frequency of Menopausal Symptoms in Northern Iran. Medical Journal Iran Red Crescent Med.; 13(3):192198

5. Dhillon H., Singh H., Rashidah S., Abdul Manaf H., Nik and Mohd Zaki N., (2006): Prevalence of menopausal symptoms in women in Kelantan, Malaysia. Maturitas, 54:213-221.

6. Gharaibeh M., Al-Obeisat S., Hattab J., (2010): Severity of menopausal symptoms of Jordanian women. Climacteric, 13: (4), 385-394.

7. Heinemenn L., Pottoff P, Schneider H., (2003): International version of the menopausal rating scale (MRS). Health Qual Life Outcomes 2003;

28.http://www.biomedcentral.com/content/suppl ementary/1477-7525-1-28-53.pdf

8. Lu J., Liu J., Eden J., (2007): The experience of menopausal symptoms by Arabic women in Sydney. Climacteric, 10:72-77.

9. Palacios S., Henderson V., Siseles N., Tan D., and Villaseca P., (2010): Age of menopause and impact of climacteric symptoms by geographical region. Climacteric, 13:419-428 .

10. Pensri R, Siriporn C., and Milica M (2007): Quality of Life Perceptions of Middle-Aged Women Living with a Disability in Muang District, KhonKaen,Thailand: WHOQOL Perspective. J Med Assoc Thai., 90 (8): 1640-6.

11. Rahman S, Zainudin S, and Kar Mun V., (2010): Assessment of menopausal symptoms using modified Menopause Rating Scale (MRS) among middle age women in Kuching, Sarawak, Malaysia. Asia Pacific Family Medicine, 9:5.

12. Rahman S., Salehin F., and Asif Iqbal1 (2011): Menopausal symptoms assessment among middle age women in Kushtia, Bangladesh. BMC Research Notes, 4:188 http://www.biomedcentral.com/17560500/4/188 32.

13. Royal College of Nursing (2009): Competences: an integrated career and competence framework for nurses and health care support workers working in the field of menopause, London: RCN.

14. Sallam H., 232 Galal A., And Rashed A., (2006): Menopause in Egypt: past and present perspectives, The Suzanne Mubarak Regional Center for Women's Health and Development, Egypt, 9 (6): 421-429.

15. Skevington S., Lofty M., O'Connell K., Whoqol Group. (2004) : The World Health Organization's WHOQOL- Breif quality of life assessment: psychometric properties and results of the international field trial. A report from 
WHOQOL group. Qual Life Re2004; 13:299310.

16. Thacker, H., (2011) : "Assessing risks and benefits of non-hormonal treatments for vasomotor symptoms in perimenopausal and postmenopausal women.". J., Womens Health 20 (7): 1007-16. doi:10.1089/jwh.2010.2403. PMID 21675874.

17. Twiss J., Wegner J., Hunter M., Kelsay M., Rathe-Hart M., Salado W., (2007): "Perimenopausal symptoms, quality of life, and health behaviors in users and nonusers of hormone therapy". J Am Acad Nurse Pract 19 (11): 602-13.

18. Walker M., and Herndon J., (2008): "Menopause in nonhuman primates?". Biology of Reproduction 79 (3): 398-406. Doi: 10.1095/biolreprod.108.068536.PMC 2553520.P MID 18495681//www.pubmedcentral.nih.gov/art iclerender.fcgi?tool=pmcentrez\&artid=2553520.

19. Yakout S., kamal S., and Moawed S., (2011): Menopausal Symptoms and Quality of Life among Saudi Women in Riyadh and Taif, Journal of American Science,7(5): 778-782. 